\title{
How should we feed the world?
}

\author{
Review by Nathan Collins* \\ University of Kansas
}

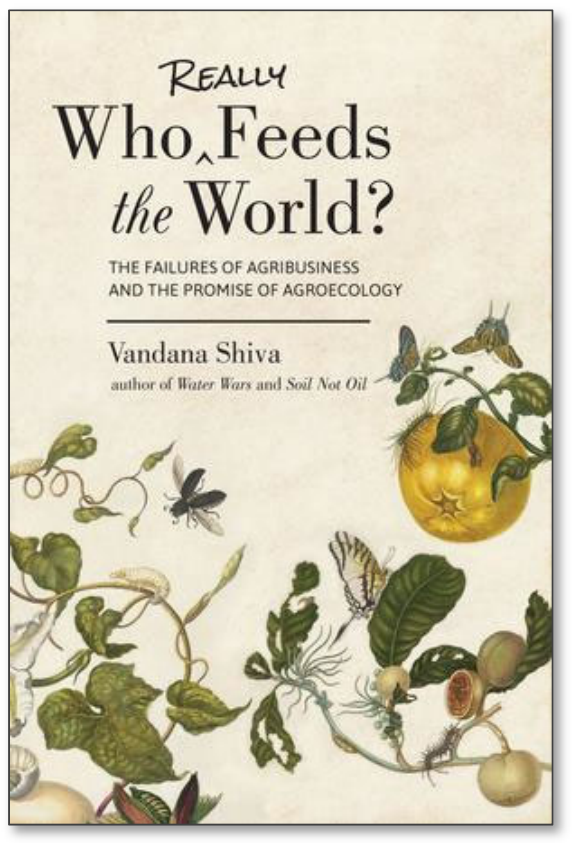

Submitted February 18, 2017 / Published online June 25, 2017

Citation: Collins, N. (2017). How should we feed the world? [Book review]. Journal of Agriculture, Food Systems, and Community Development, 7(3), 215-216. http://dx.doi.org/10.5304/jafscd.2017.073.005

Copyright (C) 2017 by New Leaf Associates, Inc.

$\mathrm{V}$ andana Shiva's Who Really Feeds the World? focuses on the ever more critical issue of food security. Throughout the book, Shiva juxtaposes the current global food system and her feminist agroecological solution to demonstrate the failing of the former and the potential of the latter. Each chapter does an excellent job of laying out the shortcomings of the current agribusiness model. The author pulls no punches and makes no

* Nathan Collins is a PhD student in sociology at the University of Kansas. He is currently focusing on issues related to the environment, labor, and the impact of patenting seeds that came about with the creation of GMOs and/or patentable germplasm. Nathan's recent research emphasizes the impact that the patenting of seeds has had on farmers' labor, autonomy, and prosperity. He can be reached at nrcollins@ku.edu. attempt to hide her position that agroecology feeds our planet, while agribusiness is slowly killing it. There is little in the way of nuance; her goal is clearly to out agribusiness as being at "war" with the planet and the life that depends on it. To validate this claim, the author describes several areas in which agribusiness has served to destroy a diversity of life and may end up severely damaging the planet's food sources.

Shiva identifies a deep and growing food crisis in her introduction, and from there begins to explain two adversarial agricultural paradigms as she sees them. The first paradigm is the cause of the current food crises-not as an accident but as a basic aspect of the paradigm's design. This paradigm separates humanity from nature and emphasizes the commodification of the planet's bounty. 
The second paradigm is the solution to the current food crisis. The second paradigm calls for a return to "traditional" small-scale farming and away from the perception that seed and soil are dead material to be used by humanity. It emphasizes humanity's place as a part of nature and renewal, returning to the earth that which we take.

Each chapter follows a simple and consistent framework of comparing the two paradigms to dispel misconceptions promoted by agribusiness corporations. The pattern is clear from the title, Who Really Feeds the World?, and from each subsequent chapter heading such as "Biodiversity feeds the world, not poisons and pesticides," "Women feed the world, not corporations" or "Localization feeds the world, not globalization." These chapters emphasize the two paradigms and the beliefs and values that follow when people accept one paradigm or the other. The differences between the two paradigms are seemingly endless; even their basic definitions of what food is do not align.

Each chapter oscillates between outlining the current failings of agribusiness and outlining the potential benefits of adopting agroecological ways of farming. Anyone who loves Shiva's work or ecological activism, in general, will enjoy this text; however, for others it may be less useful. This book, while enlightening for those unaware of current global ecological issues, adds little to the discussion. Who Really Feeds the World? serves as a rallying cry more than a deep critique. Shiva undoubtedly understands the immensity of the problem she is describing, but her analysis often falls short of the full scale of the issue when suggesting agroecological responses.

If, as she convincingly argues, the agribusiness model is so detrimental to the world, why is it so pervasive? If agroecology is superior, why do so many refuse to use it? She puts some of the blame on international politics (farm subsidies in the global north and trade deregulation devastating global markets); however, these issues do not explain why those in the global north prefer genetically modified seeds and monocropping. A deeper exploration of economic pressures would more thoroughly explain the current state of food production. For example, the role of the International Monetary Fund (IMF) and World Bank in pushing monocropping, and the focus on commodity production in countries struggling to feed themselves, should not be ignored. Additional emphasis on the benefits of genetically modified crops as superior commodity crops, when coupled with an explanation of the problematic nature of this style of agriculture, could ultimately flesh out the issue without undermining Shiva's argument. Commodity crops may, in fact, be worse when looked at using an input-to-nutrition scale, as Shiva does, but this is not the measure used by the large corporations benefiting from the sale of these products. The lack of emphasis on the benefits of commodity crops for those who produce them results in a straw man for Shiva to knock down rather than a more nuanced argument against the practice. Another shortcoming is Shiva's use of wellness models with no regard or explanation for the rubrics her adversaries use in analyzing the same practice. This is not to discount Shiva's position nor the issues she raises; however, in order to dismantle a dominant paradigm, it may be better to use, or at least reference, the master's tools.

While the author's argument for agroecology suffers from an incomplete comparison with its adversary, the overall explanation of the problem concerning food sovereignty is excellent. The importance of reclaiming control over the idea of food-reframing it as sustenance rather than commodity - cannot be overstated. Vandana Shiva understands the failures of the current system and outlines them clearly. There may be no one better to explain agroecology than Shiva, with her extensive knowledge of and experience with its implementation. The book reflects her expertise and can serve as an extensive guide to the failings of the current system. 